\title{
P-glycoprotein deficiency at the blood-brain barrier increases amyloid- $\beta$ deposition in an Alzheimer disease mouse model
}

\author{
John R. Cirrito, ${ }^{1}$ Rashid Deane, ${ }^{2}$ Anne M. Fagan, ${ }^{1,3}$ Michael L. Spinner, ${ }^{1}$ Maia Parsadanian, ${ }^{1}$ \\ Mary Beth Finn, ${ }^{1}$ Hong Jiang, ${ }^{1}$ Julie L. Prior, ${ }^{4}$ Abhay Sagare, ${ }^{2}$ Kelly R. Bales, ${ }^{5}$ Steven M. Paul, ${ }^{5}$ \\ Berislav V. Zlokovic, ${ }^{2}$ David Piwnica-Worms, ${ }^{4,6}$ and David M. Holtzman ${ }^{1,3,6}$

\begin{abstract}
1Department of Neurology, Washington University Medical School, St. Louis, Missouri, USA. ${ }^{2}$ Frank P. Smith Laboratories for Neuroscience and Neurosurgical Research, Department of Neurosurgery, University of Rochester Medical Center, Rochester, New York, USA.

${ }^{3}$ Hope Center for Neurological Disorders and ${ }^{4}$ Molecular Imaging Center, Mallinckrodt Institute of Radiology, Washington University Medical School, St. Louis, Missouri, USA. ${ }^{5}$ Neuroscience Discovery Research, Lilly Research Laboratories, Indianapolis, Indiana, USA.
\end{abstract} \\ ${ }^{6}$ Department of Molecular Biology and Pharmacology, Washington University Medical School, St. Louis, Missouri, USA.
}

\begin{abstract}
Accumulation of amyloid- $\beta(A \beta)$ within extracellular spaces of the brain is a hallmark of Alzheimer disease (AD). In sporadic, late-onset $A D$, there is little evidence for increased $A \beta$ production, suggesting that decreased elimination from the brain may contribute to elevated levels of $A \beta$ and plaque formation. Efflux transport of $A \beta$ across the blood-brain barrier (BBB) contributes to $A \beta$ removal from the brain. P-glycoprotein (Pgp) is highly expressed on the luminal surface of brain capillary endothelial cells and contributes to the BBB. In Pgp-null mice, we show that $\left[{ }^{125} \mathrm{I}\right] \mathrm{A} \beta_{40}$ and $\left[{ }^{125} \mathrm{I}\right] \mathrm{A} \beta_{42}$ microinjected into the CNS clear at half the rate that they do in WT mice. When amyloid precursor protein-transgenic (APP-transgenic) mice were administered a Pgp inhibitor, $A \beta$ levels within the brain interstitial fluid significantly increased within hours of treatment. Furthermore, APP-transgenic, PgP-null mice had increased levels of brain A $\beta$ and enhanced A $\beta$ deposition compared with APP-transgenic, Pgp WT mice. These data establish a direct link between Pgp and $A \beta$ metabolism in vivo and suggest that Pgp activity at the BBB could affect risk for developing AD as well as provide a novel diagnostic and therapeutic target.
\end{abstract}

\section{Introduction}

Conversion of amyloid- $\beta(\mathrm{A} \beta)$ within the extracellular spaces of the brain into toxic soluble and insoluble forms is accelerated at higher concentrations, implying that pathways influencing $A \beta$ production or elimination could potentially modulate disease progression. $A \beta$ is secreted from neurons into brain interstitial fluid (ISF), where it is eliminated by proteolytic degradation $(1,2)$, passive bulk flow (3), and active transport across the blood-brain barrier (BBB) $(4,5)$. The latter, representing efflux across the BBB into the periphery, appears to be a substantial pathway for elimination of CNS-derived $A \beta(5)$. It has been demonstrated that lowdensity lipoprotein receptor-related protein (LRP1) is a major A $\beta$ efflux transporter at the $\mathrm{BBB}(6)$; however, other $\mathrm{A} \beta$ transporters likely exist as well $(7,8)$. P-glycoprotein (Pgp; ABCB1), the 170-kD protein product of the multidrug resistance-1 (MDR1) gene, when overexpressed in tumor cells, confers multidrug resistance due to efflux transport of a variety of cytotoxic agents (9). Pgp is also highly expressed on the luminal surface of brain capillary endothelial cells, wherein Pgp functionally constitutes a major component of the BBB by limiting CNS penetration of various chemotherapeutic agents, small peptides, antibiotics, HIV protease inhibitors, and antidepressant drugs $(10,11)$. In mice, Pgp is encoded by both

Nonstandard abbreviations used: $A \beta$, amyloid- $\beta$; AD, Alzheimer disease; APP, amyloid precursor protein; BBB, blood-brain barrier; ISF, interstitial fluid; LRP1, lowdensity lipoprotein receptor-related protein 1; MDR1, multidrug resistance-1; Pgp, P-glycoprotein; RAGE, receptor for advanced glycation endproducts.

Conflict of interest: The authors have declared that no conflict of interest exists.

Citation for this article: J. Clin. Invest. 115:3285-3290 (2005).

doi:10.1172/JCI25247. $m d r 1 a$ and $m d r 1 b$, which have $90 \%$ sequence homology to each other and $80 \%$ to human MDR1 (10). Thus, double-knockout mice lacking both $m d r 1 a$ and $m d r 1 b$ completely eliminate Pgp activity at the BBB. Using an inside-out membrane vesicle preparation, Lam and colleagues provide in vitro biochemical data suggesting that $A \beta$ may be a substrate for Pgp transport (12). Interestingly, regionspecific levels of $A \beta$ deposition in post-mortem Alzheimer disease (AD) brain are inversely correlated to the level of Pgp in brain vasculature as assessed by immunohistochemistry (13). Herein, we demonstrate using Pgp-null mice that $A \beta$ removal from the brain is at least partially mediated by Pgp on the BBB. Similarly, acute inhibition of Pgp activity, using a selective Pgp inhibitor, increases $\mathrm{A} \beta$ levels in brain ISF within hours of treatment. Furthermore, the lack of Pgp expression exacerbates $A \beta$ deposition in a mouse model of $\mathrm{AD}$. These data strongly suggest that Pgp normally transports $A \beta$ out of the brain and that perturbation of $A \beta$ efflux directly affects $A \beta$ accumulation within the brain.

\section{Results}

To directly assess the role of Pgp in transport of $A \beta$ across the BBB, we first microinjected $\left[{ }^{125} \mathrm{I}\right] \mathrm{A} \beta_{40}$ or $\left[{ }^{125} \mathrm{I}\right] \mathrm{A} \beta_{42}$ into the brains of $m d r 1 a / b^{-/-}$double-knockout (Pgp-null) mice and WT controls (7). $\left[{ }^{14} \mathrm{C}\right]$ inulin, a reference molecule that is neither actively transported across the $\mathrm{BBB}$ or retained within the brain, was coadministered to measure bulk flow of ISF in the same mice. Thirty minutes following coadministration of tracers, mice were sacrificed, and the content of each compound remaining in the brain was assessed (Figure 1, $A$ and $C)$. Significantly more $\left[{ }^{125} \mathrm{I}\right] \mathrm{A} \beta_{40}$ and $\left[{ }^{125} \mathrm{I}\right] \mathrm{A} \beta_{42}$ were retained within the brains of Pgp-null animals compared with Pgp WT mice 

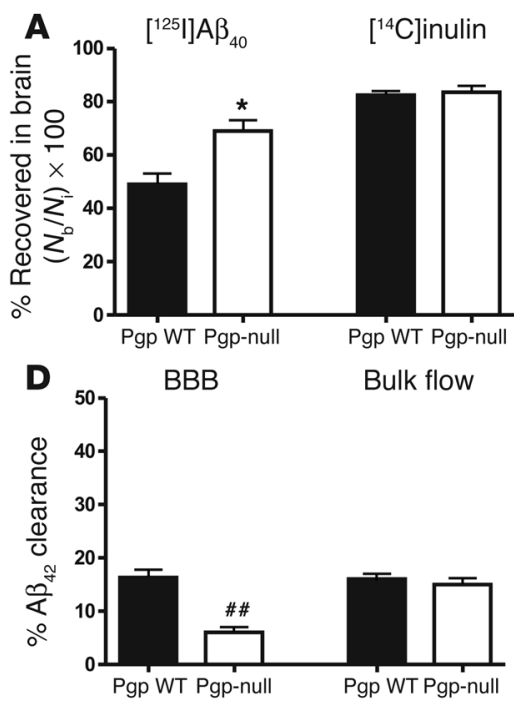

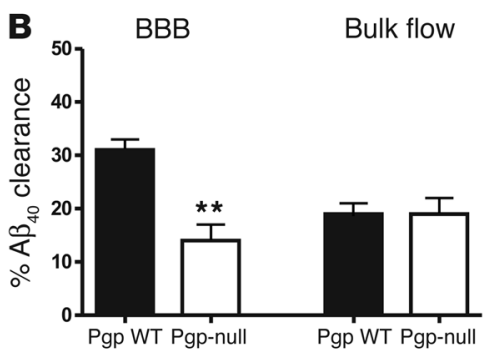

E

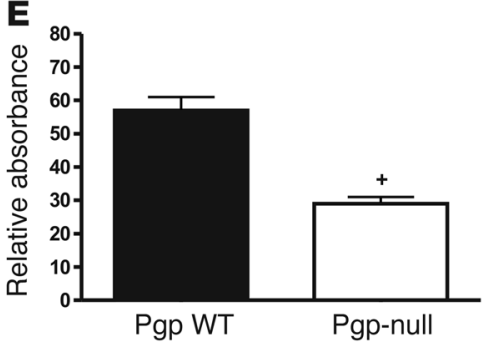

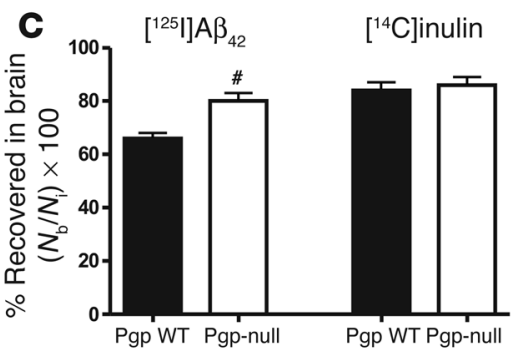

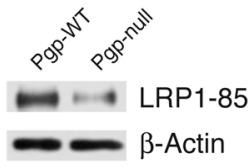

\section{Figure 1}

Clearance of [125]]A $\beta 40$ and [125I]A 342 from the brain after intracerebral microinjection. Two- to 3-month-old WT FVB and $m d r 1 a / b^{-/-}$mice on an FVB background were injected with $12 \mathrm{nmol}\left[{ }^{125}\right] \mathrm{A} \beta_{40}$ or [ [125I]A $\beta_{42}$ into the striatum. Clearance of each peptide was assessed 30 minutes after treatment. $\left[{ }^{14} \mathrm{C}\right]$ inulin, an inert reference molecule, was coinjected in each experiment to assess bulk flow elimination of ISF. (A) Brain recovery $\left(N_{\mathrm{b}} / N_{\mathrm{i}}\right)$ of $\left[{ }^{125} \mathrm{I}\right] \mathrm{A} \beta_{40}$ (left) and $\left[{ }^{14} \mathrm{C}\right]$ inulin (right). Significantly more $\left[{ }^{125} \mathrm{I}\right] \mathrm{A} \beta_{40}$ was recovered in the brains of Pgp-null than Pgp WT mice $\left({ }^{*} P=0.0123\right)$. Similar levels of injected $\left[{ }^{14} \mathrm{C}\right]$ inulin were recovered in both groups. (B) Calculation of $\left.\left[{ }^{125}\right]\right] A \beta_{40}$ clearance via the BBB and ISF bulk flow mechanisms (from data shown in A). Significantly less $A \beta_{40}$ was cleared via the BBB in Pgp-null mice compared with Pgp WT mice $\left({ }^{* *} P=0.0033\right)$. (C) Brain recovery of $\left[{ }^{125} \mid\right] A \beta_{42}$ (left) and $\left[{ }^{14} \mathrm{C}\right]$ inulin (right). More $\left[{ }^{125}\right] \mathrm{A} \beta_{42}$ was cleared from the brain in Pgp WT than Pgp-null mice ( $P=0.0047$ ). Approximately $85 \%$ of $\left[{ }^{14} \mathrm{C}\right]$ inulin was retained in both groups. (D) Similar to calculations for $A \beta_{40}$ clearance, significantly less $A \beta_{42}$ was cleared from the brain of Pgp-null mice $(\# P=0.0004)$. (E) LRP1 expression was decreased by $51 \%$ in cerebral vessels of 2 - to 3-month-old Pgp-null mice compared with WT FVB controls $\left({ }^{+} P=0.002\right)$. Left: Relative absorbance representing the signal obtained from the $85-\mathrm{kDa}$ LRP band on the Western blots normalized to the loading control is shown on the $y$ axis. Right: representative lanes from an 85-kDa LRP1 peptide (LRP1-85) Western blot and protein loading control. Values are mean \pm SEM; $n=4-8$ per group.

( $P=0.0123$ and $P=0.0047$, respectively), strongly suggesting that $\mathrm{A} \beta$ elimination was hindered in these animals. Removal of $\left[{ }^{3} \mathrm{H}\right]$ leucine, a Pgp-independent, actively transported molecule, was unaffected at 10 minutes after injection $(61.4 \% \pm 3.8 \%$ and $62.7 \% \pm 5 \%$ retained in Pgp WT [FVB] versus Pgp-null, respectively). Similarly, bulk flow pathways, accounting for less than $20 \%$ of clearance, appeared unchanged in the knockout animals as demonstrated by nearly identical levels of inulin remaining in both groups. As shown in Figure 1B, after passive elimination was taken into account, $31 \%$ of injected $A \beta_{40}$ was transported across the BBB in WT mice, whereas only approximately $14 \%$ was cleared in the Pgp-null animals $(P=0.0033)$. Similarly, $16 \%$ of $A \beta_{42}$ was transported in Pgp WT mice compared with $6 \%$ in Pgp-null mice (Figure 1D). Compared with $A \beta_{40}$, significantly less $A \beta_{42}$ was removed from the brain in WT and Pgp-null mice, which is consistent with previous studies showing that $A \beta_{40}$ is generally actively transported across the $\mathrm{BBB}$ more than $A \beta_{42}(7)$. LRP1 has been previously shown to transport $A \beta$ across the $\operatorname{BBB}(5,7)$. While overall levels of LRP1 in brain homogenates were comparable (data not shown), interestingly, levels of LRP1 decreased by $50 \%$ in brain capillaries of 2- to 3-month-old Pgp-null mice as compared with PgP WT mice (Figure 1E). This decrease in LRP1 expression at the BBB may have partially contributed to decreased $A \beta$ clearance in Pgp-null mice.

Next, we assessed how acute inhibition of Pgp activity affected brain ISF A $\beta$ levels. We utilized APPsw (also called Tg2576) mice, which overexpress human amyloid precursor protein (APP), with a mutation that in humans causes an autosomal dominant form of early-onset familial AD (14). A selective Pgp inhibitor, XR9576 (15), was used to block Pgp activity at the BBB in APPsw mice. Because brain capillary endothelial cells transport molecules out of the brain ISF into the periphery, we directly assessed this fluid for changes in $A \beta$ levels following intravenous administration of XR9576 at $80 \mathrm{mg} / \mathrm{kg}$, a dose that inhibits Pgp function at the $\mathrm{BBB}$, as determined by [ $\left.{ }^{99 \mathrm{~m}} \mathrm{Tc}\right]$ Sestamibi analysis (data not shown). Using in vivo microdialysis in awake, freely moving mice $(16,17)$, we first determined a basal concentration of ISF A $\beta$ over 5 hours, then treated mice with either vehicle or XR9576 and continued to assess ISF A $\beta$ levels for an additional 10 hours (Figure 2A). Eight hours after treatment, ISF A $\beta$ levels increased almost 30\% compared with vehicle-treated mice $(P<0.05)$, suggesting that acute inhibition of Pgp at the BBB caused decreased elimination of $A \beta$ from brain ISF. Ten hours after treatment with either vehicle or XR9576, cerebral microvessels were also isolated and assessed for levels of LRP1 by Western blotting. LRP1 levels in endothelial cells did not change (Figure 2B), indicating that, in this case, the change in ISF A $\beta$ levels is not attributable to LRP1 downregulation but is likely due to specific inhibition of Pgp.

Next, we determined whether the absence of Pgp at the BBB would promote $\mathrm{A} \beta$ deposition. We bred $A P P s w^{+/-}$mice to $m d r 1 a / b^{-/-}$ animals to produce littermate mice that were positive for the $A P P s w$ transgene and either Pgp-null $\left(A P P s w^{+/-}, m d r 1 a / b^{-/-}\right)$or Pgp WT $\left(A P P s w^{+-}, m d r 1 a / b^{+/+}\right)$. To confirm that transgenic expression of mutated human APP did not impact basal function of Pgp in vivo, biodistribution studies utilizing $\left[{ }^{99} \mathrm{~m} \mathrm{Tc}\right]$ Sestamibi, a radio- 

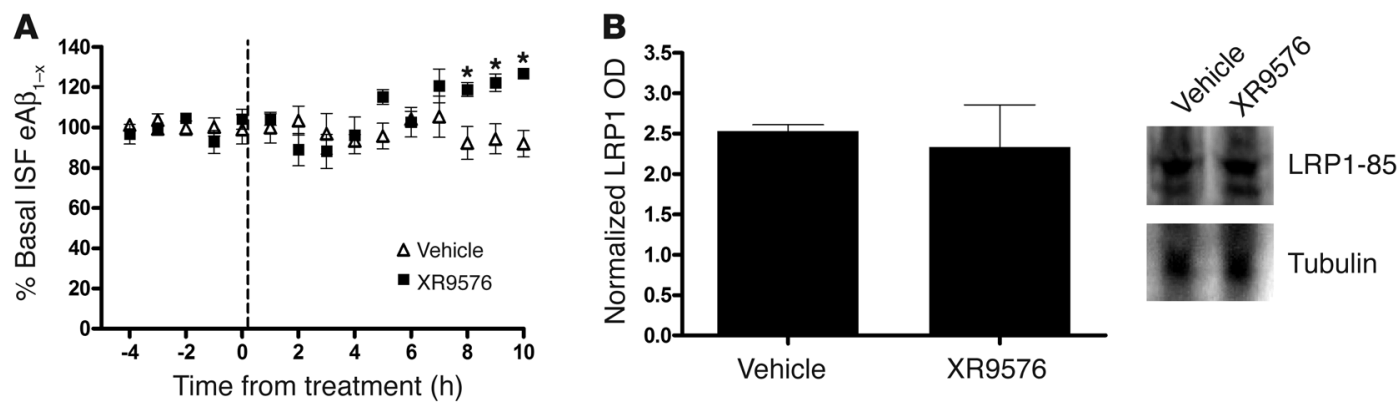

Figure 2

Acute inhibition of Pgp increases $A \beta$ levels in brain ISF. Using in vivo microdialysis, we assessed the concentration of ISF A $\beta_{1-x}$ within the hippocampus of 3-month-old APPsw mice treated with XR9576, a Pgp inhibitor. For each animal, basal concentration of ISF A $\beta_{1-x}$ was established over 5 hours, followed by intravenous injection of XR9576 and continued assessment of ISF A $\beta$ for an additional 10 hours. Samples were collected at hourly intervals and assessed for $A \beta_{1-x}$ using a sandwich ELISA. (A) Eight hours after intravenous administration of $80 \mathrm{mg} / \mathrm{kg}$ XR9576, ISF exchangeable $A \beta_{1-\mathrm{x}}\left(\mathrm{eA} \beta_{1-\mathrm{x}}\right)$ levels began to increase and reached $127.7 \% \pm 3.4 \%$ of control-treated (vehicle-treated) mice $\left({ }^{*} P<0.05 ; n=5\right.$ per group). (B) Ten hours after treatment with either XR9576 or vehicle, cerebral capillaries were isolated and analyzed for levels of LRP1 expression by Western blotting ( $n=5$ per group). Levels of LRP1 in cerebral vessels did not change with acute inhibition of Pgp.

pharmaceutical that has been validated as a sensitive probe of Pgp transport function (18), were performed in 2- to 4-month-old WT $\left(m d r 1 a / b^{+/+}\right)$and Pgp-null $\left(m d r 1 a / b^{-/-}\right)$mice, both in the absence and presence of the APPsw $w^{+/-}$transgene. Normally, [99m Tc]Sestamibi is readily transported out of the brain by Pgp. However, in Pgp-null animals, $\left[{ }^{99 \mathrm{~m}} \mathrm{Tc}\right]$ Sestamibi levels increase in the brain as it permeates cerebral capillaries and is not removed effectively. Five minutes after intravenous bolus injection of [ $\left.{ }^{99 \mathrm{~m}} \mathrm{Tc}\right]$ Sestamibi $(2 \mu \mathrm{Ci})$, brain content of the tracer was $0.22 \% \pm 0.02 \%$ injected dose $/ g(I D / g)$ in WT controls versus $0.85 \% \pm 0.14 \% \mathrm{ID} / \mathrm{g}$ in Pgp-null mice (Figure 3 ). There was no difference in blood content of the tracer between the 2 strains $(P>0.2)$. This approximately 3.5 -fold increase in brain penetration of [ $\left.{ }^{99 \mathrm{~m}} \mathrm{Tc}\right]$ Sestamibi in Pgp-null mice was consistent with previous studies (19). In animals of similar age that expressed the $A P P s w^{+/-}$transgene, brain penetration of the tracer was also increased by approximately 3.5-fold in Pgp-null animals compared with those expressing Pgp (Figure 3). Thus, basal activity of Pgp was independent of the APPs $w^{+/-}$transgene $(P>0.3)$.

When allowed to survive to 12 months, $A P P s w^{+/-}$mice exhibited substantial A $\beta$ deposition throughout the neocortex and hippocampus (Figure 4, A and B). The area covered by A $\beta$ immunoreactivity in the hippocampus was significantly greater in APPsw, PgP-null animals compared with APPsw, PgP WT littermates $(P=0.0041$; Figure $4 \mathrm{C})$. The amount of fibrillar $\mathrm{A} \beta$, as determined by thioflavine $\mathrm{S}$ staining, was also significantly elevated in Pgpnull animals $(P=0.0276$; Figure 4D). However, when the amount of thioflavine $S$ was normalized to total plaque load, there was not a significant difference in the percentage of fibrillar plaques between groups (Figure 4E). This suggests that while Pgp deletion leads to greater $A \beta$ deposition, Pgp does not preferentially alter the conversion of plaques into fibrillar structures. There was no apparent change in the amount of vascular $A \beta$ accumulation in 12-month-old Pgp-null animals; however, it remains possible that at later ages, when there is a greater amount of cerebral amyloid angiopathy, there may be a noticeable affect. The mass of insoluble $A \beta_{42}$, as assessed by guanidine extraction and $A \beta$ ELISA, was 2-fold greater in the hippocampus of Pgp-null animals $(P=0.0499$; Figure $4 \mathrm{~F})$, while there was only a trend toward an increase in insoluble $A \beta_{40}(P=0.2472$; Figure $4 G)$. Carbonate-extractable $A \beta_{40}$ and $A \beta_{42}$ was not different between these groups (data not shown). Similar to the hippocampus, there was a trend toward elevated $A \beta$ plaque load in the neocortex of Pgp-null mice; however, this increase was not statistically significant (Figure 4H). These findings indicate that abrogation of the Pgp transporter at the $\mathrm{BBB}$ gave rise to greater $\mathrm{A} \beta$ accumulation within the brain and suggest that modulation of Pgp activity can directly influence progression of $A \beta$ pathology. Because genetic deletion of Pgp also causes a decrease in the level of LRP1 at the $\mathrm{BBB}$ (Figure 1), it remains possible that the changes in $\mathrm{A} \beta$ deposition are due to a combined decrease in both $A \beta$ transporters. In fact, these $A \beta$ transporters may be playing a synergistic role, with LRP1 functional on the basolateral surface and Pgp on the luminal surface of brain endothelial cells.

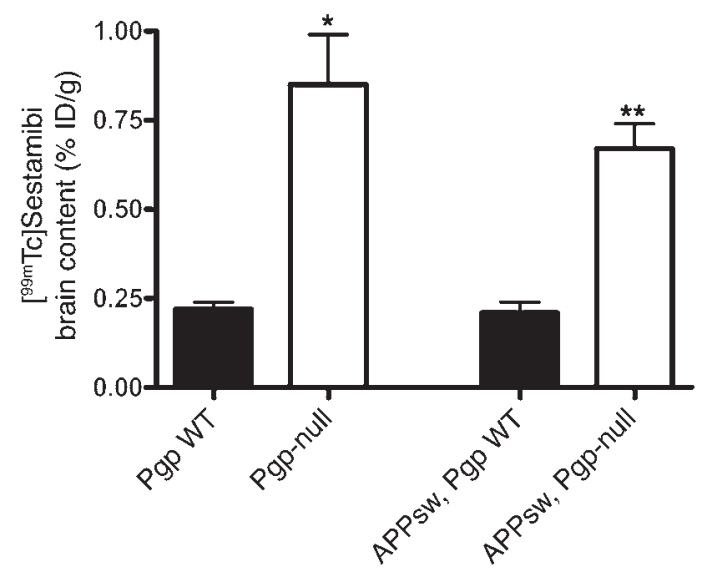

Figure 3

Biodistribution of a Pgp substrate in APPsw, Pgp-null mice. Following tail vein bolus injection of $2 \mu \mathrm{Ci}\left[{ }^{99 \mathrm{mT}} \mathrm{Tc}\right]$ Sestamibi, brain content of [99mTc]Sestamibi in 2- to 4-month-old WT and Pgp-null mice (on an FVB background), as well as APPsw mice expressing or lacking Pgp, was determined 5 minutes after injection. More tracer was retained in all Pgp-null mice $\left({ }^{*} P=0.0043\right.$, FVB strain; ${ }^{* \star} P=0.0058, A P P s w^{+/-}$strain), demonstrating, as expected, that Pgp normally hinders the entry of [99mTc]Sestamibi into the brain. Taken together, these finding suggest that Pgp expressed on the BBB behaves similarly in WT and APPsw mice. ID, injected dose. 

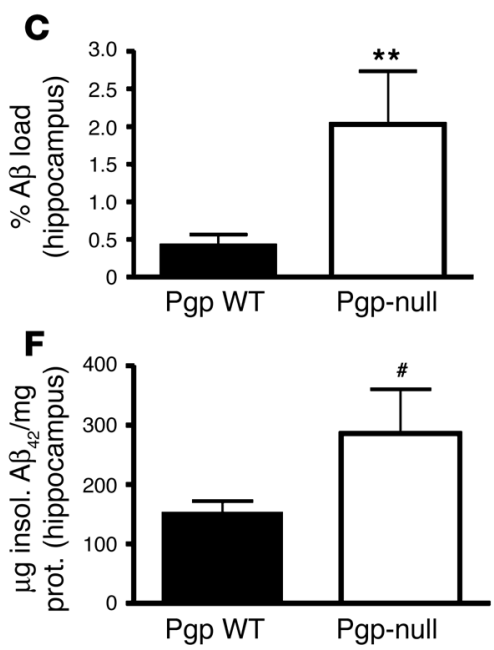

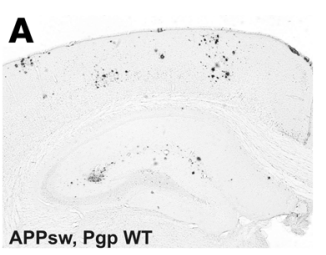

D
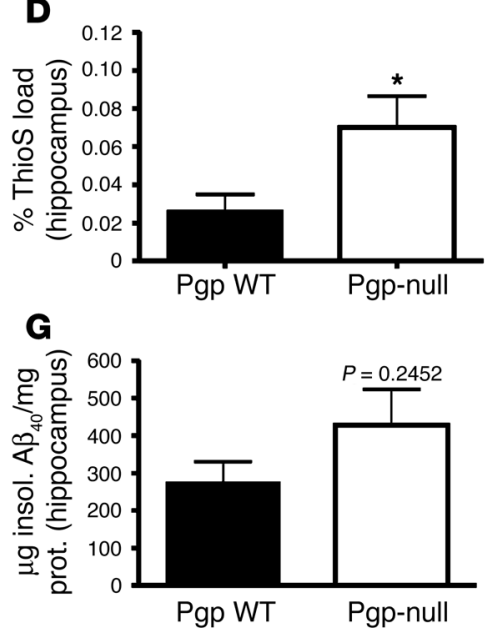
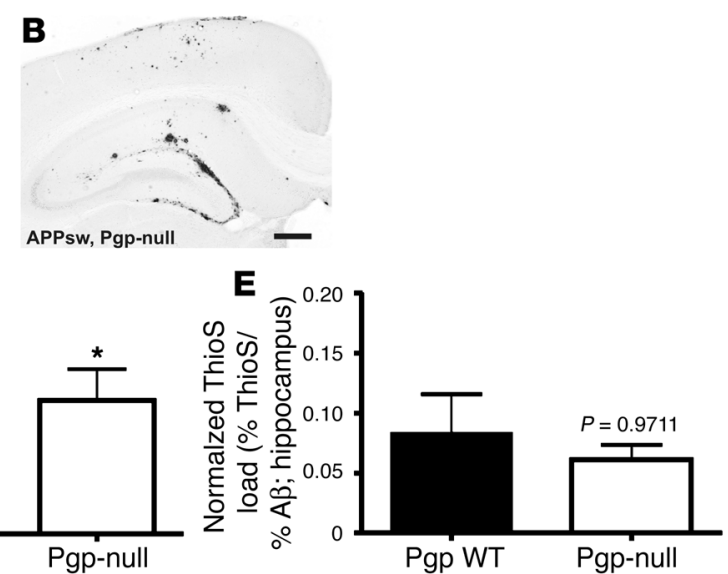

H

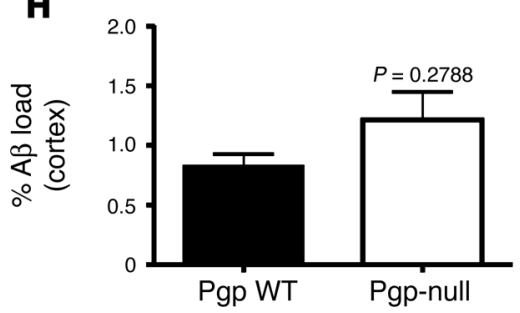

Figure 4

Increased $A \beta$ accumulation in APPsw, Pgp-null mice. (A and B) Brain sections from APPsw mice expressing or lacking Pgp were stained with an anti-A $\beta$ antibody. Twelve-month-old APPsw, Pgp-null $\left(\mathrm{mdr1} \mathrm{a} / \mathrm{b}^{-/-}\right)$mice showed greater $\mathrm{A} \beta$ deposition within the hippocampus and cortex than their Pgp WT littermates. Scale bar: $250 \mu \mathrm{m}$. (C) As quantified by unbiased stereological techniques, Pgp-null mice exhibited a greater percentage of the hippocampus covered by $A \beta$ immunoreactivity (\% A $\beta$ load) than Pgp WT mice; ${ }^{* *} P=0.0041$. The pattern of $A \beta$ deposition within the hippocampus was similar in both genotypes. (D) In addition, the amount of fibrillar $A \beta$, as assessed by the percent area of hippocampus covered by thioflavine $S$ staining (\% ThioS load), was also increased in Pgp-null animals; ${ }^{\star} P=0.0276$. (E) However, when normalized to $A \beta$ immunoreactivity, the percentage of fibrillar $A \beta$ to total $A \beta$ deposits was not different between the groups; $P=0.9711$. (F) Fresh hippocampal tissue was sequentially extracted with carbonate, then guanidine and A $\beta$ ELISA was performed on the extracts. $A \beta$ levels within each homogenate were normalized to the protein (prot.) content. Guanidine-extracted, insoluble (insol.) A $\beta_{42}$ was significantly elevated in Pgp-null mice ( $P=0.0499$ ), while there was only a trend toward elevated insoluble $A \beta_{40}(P=0.2452)(\mathbf{G})$. (H) Similar to the hippocampus, there was also a trend for greater $\mathrm{A} \beta$ immunoreactivity within the cortex of Pgp-null animals; $P=0.2788$. Values are mean $\pm \mathrm{SEM} ; n=11-16$ per group.

Pgp shares sequence homology and substantial pharmacological cross-reactivity with several members of the ATP-binding cassette superfamily of transporters that are also expressed at the $\mathrm{BBB}$, including multidrug-resistance-associated protein-1 (MRP1, also known as ABCC1) (9). In 12-month-old APPsw, Pgp-null $\left(A P P s w^{+/-}, m d r 1 a / b^{-/-}\right)$mice, expression of MRP1 in hippocampal homogenates was elevated compared with PgP WT $\left(A P P s w^{+/}\right.$, $\left.m d r 1 a / b^{+/+}\right)$mice $(P=0.0401$; data not shown). Although Pgp and MRP1 have overlapping pharmacological profiles, it is unknown whether MRP1 can also transport $A \beta$ in vivo. In vitro studies suggest that MRP1 cannot transport $A \beta$ (12). Receptor for advanced glycation endproducts (RAGE), a transporter on the $\mathrm{BBB}$ that is responsible for transporting $A \beta$ from the blood into the brain (20, 21), was expressed at similar levels in hippocampal homogenates of 12-month-old APPsw, Pgp-null and APPsw, Pgp WT mice (data not shown). The potential contribution of each of these transporters to $A \beta$ clearance from the brain and how they might interact or compensate for each other requires further investigation.

\section{Discussion}

Herein, we demonstrate that Pgp is involved in the transport of $\mathrm{A} \beta$ across the $\mathrm{BBB}$ in vivo and that ablation of Pgp at the $\mathrm{BBB}$ enhances $A \beta$ deposition. While Pgp deletion has not been reported in humans, several mechanisms for modulation of Pgp activity at the BBB could influence AD. Several Pgp single nucleotide polymorphisms, such as the exon 263435 T allele, have been described that decrease Pgp expression and result in functional differences in oral absorption and disposition of drugs (22). It is conceivable that similar polymorphisms in Pgp could decrease $A \beta$ transport out of the brain, thereby increasing the probability of plaque formation. Conversely, polymorphisms that increase Pgp transport activity may decrease the risk of $A \beta$ deposition and development of AD. A detailed genetic analysis of Pgp polymorphisms in relation to $\mathrm{AD}$ in humans could test this hypothesis.

In addition to the impact of genetic polymorphisms on Pgp activity, many commonly used drugs and herbal medicinals alter Pgp function. For example, dexamethasone, morphine, rifampin, quercetin, and St. John's wort are reported to enhance Pgp activity, while verapamil, cyclosporine A, erythromycin, fluoxetine, progesterone, HIV protease inhibitors, and several statins inhibit Pgp activity (for review, see refs. 9, 23). While some of these compounds only affect Pgp activity slightly in short-term assays, with chronic use or in combination, it is possible that these drugs could have a greater effect on Pgp function and, consequently, on brain A $\beta$ levels. Since Pgp function can be modulated pharmacologically, there is potential for drugs that enhance activity to increase $A \beta$ clearance from 
the brain. For example, a randomized clinical trial demonstrated that the antibiotic rifampin lessened cognitive decline in patients with mild to moderate AD after 12 months of treatment (24). This improvement in cognitive function did not appear to be linked to the drug's antibiotic activity. Because rifampin is also a Pgp substrate and inducer, the effects of rifampin on cognitive ability may be linked to enhanced clearance of $A \beta$ from the brain via Pgp-mediated transport. An additional advantage of modulating Pgp activity is that because Pgp is expressed on the luminal surface of brain capillary endothelial cells and not within the CNS per se, drugs may not be required to cross the $\mathrm{BBB}$, a typical hurdle in developing CNS-targeted therapies. Given that a variety of genetic, therapeutic, and dietary factors can influence Pgp function, thus potentially affecting $A \beta$ transport, it will be interesting to determine whether these features correlate with the incidence of AD.

\section{Methods}

Animals. All experimental procedures involving animals were approved by the Animal Studies Committee at Washington University and performed in accordance with their guidelines. We utilized 8- to 10 -week-old $m d r 1 a / b^{-/-}$ double-knockout mice on an FVB background (Taconic) and WT controls (also on an FVB background) for our BBB transport studies. We also bred mdr1a/b-/- mice to APPsw ${ }^{+/-}$hemizygous mice (Tg2576 on a C57BL/6-SJL background; a generous gift from K. Ashe, University of Minnesota, Minneapolis, Minnesota, USA). We then bred $\mathrm{F}_{1}$ offspring from this colony to each other to produce littermate $m d r 1 a / b$ homozygous $(+/+)$ and doubleknockout (-/-) mice that were hemizygous for the APPsw $w^{+/-}$transgene. Animals were screened for the presence of APPsw as well as mdr1a and $m d r 1 b$ genes by PCR analysis of tail DNA. A $\beta$ content in the brain was analyzed when animals were 12 months old.

BBB transport. Transport of human [125 I]A $\beta_{40}\left[{ }^{125} \mathrm{I}\right] \mathrm{A} \beta_{42}$ across the BBB and calculations were performed as previously described $(4,8)$. Briefly, a guide cannula was implanted stereotaxically into the right caudate-putamen of anesthetized mice at coordinates $0.9 \mathrm{~mm}$ anterior to bregma, $1.9 \mathrm{~mm}$ lateral, and $2.9 \mathrm{~mm}$ below the dura. Animals were allowed to recover after surgery prior to radiotracer studies. The clearance experiments were performed before substantial chronic processes occurred, typically 4-6 hours following cannula implantation, to allow the BBB to at least partially repair and exclude large molecules $(8,16)$. Twelve nanomoles of $\left[{ }^{14} \mathrm{C}\right]$ inulin and either $\left[{ }^{[25} \mathrm{I}\right] \mathrm{A} \beta_{40}$ or $\left[{ }^{125} \mathrm{I}\right] \mathrm{A} \beta_{42}$ was coinjected in a volume of $0.5 \mu \mathrm{l}$ over 5 minutes using an ultra micropump (World Precision Instruments Inc.). The specific activities of peptide were in the range of $80-120 \mu \mathrm{Ci} / \mu \mathrm{g}$. The percentage of radioactivity remaining in the brain after microinjection was determined as percentage recovery in brain $=100 \times\left(N_{\mathrm{b}} / N_{\mathrm{i}}\right)$, where $N_{\mathrm{b}}$ is the radioactivity remaining in the brain at the end of the experiment and $N_{\mathrm{i}}$ is the radioactivity microinjected into brain ISF, i.e., the disintegrations per minute for $\left[{ }^{14} \mathrm{C}\right]$ inulin and the counts per minute for trichloroacetic acid-precipitable $\left[{ }^{125} \mathrm{I}\right]$ radioactivity (intact $\mathrm{A} \beta$ ). The percentage of $\mathrm{A} \beta$ cleared through the BBB was calculated as $\left[\left(1-N_{\mathrm{b}(\mathrm{AB})}\right) / N_{\mathrm{i}(\mathrm{A} \beta)}\right)-\left(1-N_{\mathrm{b}(\text { inulin })}\right)$ $\left.\left.N_{\mathrm{i}(\text { inulin })}\right)\right] \times 100$, using a standard time of 30 minutes. D- $\left[{ }^{4,5-3} \mathrm{H}\right]$ leucine (Amersham Biosciences) transport across the BBB was assessed using a method similar to that described above: $750 \mathrm{nmol}$ of $\left[{ }^{3} \mathrm{H}\right]$ leucine, specific activity $1.16 \mathrm{Ci} / \mathrm{mg}$, was injected in a volume of $0.5 \mu \mathrm{l}$ followed by measurement of radioactivity within the brain at 10 minutes.

ISF A $\beta$ in vivo microdialysis. In vivo microdialysis to assess brain ISF $A \beta_{1-\mathrm{x}}$ in the hippocampus of awake, freely moving 3-month-old $A P P s w^{+/-}$mice was performed exactly as described previously $(16,17)$. A $\beta_{1-x}$ represents all $A \beta$ peptides beginning at amino acid 1 of the $\mathrm{N}$-terminus with the $\mathrm{C}$-terminus being variable, but predominantly either ending at position 40 or 42 . An initial 4- to 6-hour recovery period elapsed after guide implantation and probe insertion to allow for tissue recovery, followed by collection of microdialysis samples for 5 hours at 1 -hour intervals at a flow rate of $1.5 \mu \mathrm{l} / \mathrm{min}$ to establish basal level of ISF A $\beta$. XR9576 (80 mg/kg body weight; Xenova QLT Inc.; diluted in $5 \%$ dextrose) or vehicle was injected into the jugular vein, and an additional 10 one-hour microdialysis samples were collected. Concentrations of ISF $A \beta_{1-\mathrm{x}}$ for each mouse were expressed as the percentage of basal level for each mouse (mean of 5 hours prior to treatment).

$\left[{ }^{99 m} T c\right]$ Sestamibi transport and biodistribution. The radiopharmaceutical [ $\left.{ }^{99 \mathrm{~m}} \mathrm{Tc}\right]$ Sestamibi (Bristol-Myers Squibb Co.) was prepared from a 1-step commercial kit formulation by addition of $\left[{ }^{99} \mathrm{mc}^{-} \mathrm{TcO}_{4}{ }^{-}\right.$according to the manufacturer's recommendations (25). Sep-Pak purification (>95\%) and quality control of the tracer were performed as previously described (25). Following intravenous injection, distribution of $\left[{ }^{99 \mathrm{~m}} \mathrm{Tc}\right]$ Sestamibi in the brain and blood of Pgp WT and Pgp-null mice with or without coexpression of $A P P s w^{+/-}$was determined 5 minutes after injection as previously described $(26,27)$. Data are expressed as percent injected dose per gram tissue $[(\mu \mathrm{Ci}$ $\left[{ }^{99 \mathrm{~m}} \mathrm{Tc}\right]$ Sestamibi in tissue) $\left.\left.\left(\mu \text { Ci injected }\left[{ }^{99 \mathrm{~m}} \mathrm{Tc}\right] \text { Sestamibi }\right)^{-1}(\mathrm{~g} \text { tissue })^{-1} \times 100\right)\right]$ and are reported as mean $\pm \operatorname{SEM}(n=3-4)$ or \pm range $(n=2)$.

Histological analysis. Tissue sections were cut in the coronal plane at $50 \mu \mathrm{m}$ on a freezing sliding microtome from the genu of the corpus callosum through the caudal extent of the hippocampus. The percent surface area covered by $A \beta$-immunoreactivity deposits (\% A $\beta$ load), as identified with a mouse monoclonal antibody against the $\mathrm{N}$ terminus of human $\mathrm{A} \beta$, m3D6 (Eli Lilly and Co.), was quantified following unbiased stereological principles as described (28). Thioflavine $S$ staining was performed stereologically and quantified as previously described (29). A $\beta$ and thioflavine $S$ load were determined in the cingulate cortex and hippocampus in 3 brain sections, each separated by $300 \mu \mathrm{m}$.

$A \beta$ quantification. $A \beta_{40}$ and $A \beta_{42}$ levels in brain tissue were determined by sandwich ELISA as previously described (16). Briefly, m266, m2G3, or m21F12 were used as coating antibodies to capture $A \beta_{1-x}, A \beta_{40}$, or $A \beta_{42}$, respectively. Biotinylated $\mathrm{m} 3 \mathrm{D} 6$, a human-specific antibody against the $\mathrm{N}$ terminus of $\mathrm{A} \beta$, was used as the reporting antibody in each ELISA. To evaluate the carbonate-soluble and -insoluble pools of $A \beta$ in brain tissue, we performed a carbonate extraction $(100 \mathrm{mM}$ carbonate, $50 \mathrm{mM} \mathrm{NaCl}$, protease inhibitors, $\mathrm{pH} 11.5)$ of hippocampal tissue (1:10, wt/vol) on ice followed by a $5 \mathrm{M}$ guanidine, $\mathrm{pH} 8.0$ extraction for 3 hours at room temp. Tissue samples were dounce homogenized and spun in a microcentrifuge at $21,000 \mathrm{~g}$ for 15 minutes at $4^{\circ} \mathrm{C}$ following each extraction.

Western blotting. Hippocampal tissue from 12-month-old APPsw, Pgp WT, and APPsw, Pgp-null littermates was homogenized in $150 \mathrm{mM} \mathrm{NaCl}, 50 \mathrm{mM}$ Tris $\mathrm{pH} 7.4,0.5 \%$ deoxycholic acid, $0.1 \%$ SDS, $1 \%$ Triton X-100, 2.5 mM EDTA, and protease inhibitors. Western blotting for MRP1, LRP1, and RAGE were performed using 3-8\% NuPAGE Tris-Acetate gels (Invitrogen Corp.) with $30 \mu \mathrm{g}$ of protein loaded per lane. Cerebral microvessels from 2- to 3-month-old Pgp WT (FVB) and Pgp-null mice were isolated as described (30). Microvessels were homogenized in cold lysis buffer: $150 \mathrm{mM} \mathrm{NaCl}, 50 \mathrm{mM}$ Tris $\mathrm{pH}$ 7.4, $0.1 \%$ SDS, $1 \%$ Triton X-100, and complete protease inhibitor cocktail (Roche Diagnostics Corp.). Individual protein homogenates were separated under nonreducing conditions, transferred to nitrocellulose membrane, and probed with rabbit anti-LRP1-85 (LRP, $\beta$-chain specific; EMD Biosciences Inc.), rabbit anti-RAGE (Santa Cruz Biotechnology Inc.), or rat anti-MRP1 (Signet Laboratories), followed by goat anti-rabbit or donkey anti-rat secondary antibodies conjugated to HRP (Jackson ImmunoResearch Laboratories Inc.). Mouse anti-tubulin (Sigma-Aldrich) or anti- $\beta$-actin (Santa Cruz Biotechnology Inc.) were used to detect control proteins in each lane. Bands were detected with Lumigen-TMA6 (Amersham Biosciences) and captured digitally using Kodak ImageStation $440 \mathrm{CF}$. The relative absorbance of each band was detected by densitometry and normalized to protein loaded in each lane. Analysis was performed using Kodak 1D Image Analysis software version 3.6. 
Statistics. Data shown in figures represent mean \pm SEM. Mann-Whitney $U$ test was used to compare data between Pgp-null and WT mice, as well as LRP1 expression levels in endothelial cells of XR9576 and vehicle-treated mice. ISF A $\beta$ levels in XR9576 and vehicle-treated mice, over the duration of the experiment, were compared by 2-way ANOVA followed by the Bonferroni post-hoc test to compare means. P values of less than 0.05 were considered statistically significant. All statistical analyses were performed using Prism version 4.02 (GraphPad Software) for Windows (Microsoft Corp.).

\section{Acknowledgments}

This study was funded by NIH grants AG13956 (to D.M. Holtzman), AG023316 (to A.M. Fagan), P50 CA94056 (to D. Piwnica-Worms), NS034467 (to B.V. Zlokovic), and AG23084 (to B.V. Zlokovic) as well as an Investigator Award from the McDonnell Center for Cellular and Molecule Neurobiology (to
A.M. Fagan) and US Department of Energy contract DE FG02 94ER61885 (to D. Piwnica-Worms).

Received for publication April 4, 2005, and accepted in revised form August 23, 2005.

Address correspondence to: David M. Holtzman, Department of Neurology, Washington University School of Medicine, 660 S. Euclid Avenue, Box 8111, St. Louis, Missouri 63110, USA. Phone: (314) 362-9872; Fax: (314) 362-2826; E-mail: holtzman@neuro. wustl.edu. Or to: David Piwnica-Worms, Mallinckrodt Institute of Radiology, Washington University School of Medicine, $510 \mathrm{~S}$. Kingshighway Boulevard, Box 8225, St. Louis, Missouri 63110, USA. Phone: (314) 362-9356; Fax: (314) 362-0152; E-mail: piwnicawormsd@mir.wustl.edu.
1. Farris, W., et al. 2003. Insulin-degrading enzyme regulates the levels of insulin, amyloid beta-protein, and the beta-amyloid precursor protein intracellular domain in vivo. Proc. Natl. Acad. Sci. U. S. A 100:4162-4167.

2. Iwata, N., et al. 2004. Presynaptic localization of neprilysin contributes to efficient clearance of amyloid-beta peptide in mouse brain. J. Neurosci. 24:991-998.

3. Weller, R.O., et al. 1998. Cerebral amyloid angiopathy: amyloid beta accumulates in putative interstitial fluid drainage pathways in Alzheimer's disease. Am. J. Pathol. 153:725-733.

4. DeMattos, R.B., Bales, K.R., Cummins, D.J., Paul, S.M., and Holtzman, D.M. 2002. Brain to plasma amyloid-beta efflux: a measure of brain amyloid burden in a mouse model of Alzheimer's disease. Science. 295:2264-2267.

5. Shibata, M., et al. 2000. Clearance of Alzheimer's amyloid-ss (1-40) peptide from brain by LDL receptor-related protein-1 at the blood-brain barrier. J. Clin. Invest. 106:1489-1499.

6. Zlokovic, B.V. 2005. Neurovascular mechanisms of Alzheimer's neurodegeneration. Trends Neurosci. 28:202-208.

7. Deane, R., et al. 2004. LRP/amyloid beta-peptide interaction mediates differential brain efflux of Abeta isoforms. Neuron. 43:333-344.

8. Zlokovic, B.V., Yamada, S., Holtzman, D., Ghiso, J., and Frangione, B. 2000. Clearance of amyloid betapeptide from brain: transport or metabolism? Nat. Med. 6:718-719.

9. Gottesman, M.M., Fojo, T., and Bates, S.E. 2002. Multidrug resistance in cancer: role of ATP-dependent transporters. Nat. Rev. Cancer. 2:48-58.

10. Ambudkar, S.V., et al. 1999. Biochemical, cellular, and pharmacological aspects of the multidrug transporter. Annu. Rev. Pharmacol. Toxicol. 39:361-398.

11. Schinkel, A.H., et al. 1994. Disruption of the mouse mdr1a P-glycoprotein gene leads to a deficiency in the blood-brain barrier and to increased sensitivity to drugs. Cell. 77:491-502.

12. Lam, F.C., et al. 2001. beta-Amyloid efflux mediated by P-glycoprotein. J. Neurochem. 76:1121-1128.

13. Vogelgesang, S., et al. 2002. Deposition of Alzheimer's beta-amyloid is inversely correlated with P-glycoprotein expression in the brains of elderly nondemented humans. Pharmacogenetics. 12:535-541.

14. Hsiao, K., et al. 1996. Correlative memory deficits, $\mathrm{A} \beta$ elevation, and amyloid plaques in transgenic mice. Science. 274:99-102.

15. Mistry, P., et al. 2001. In vitro and in vivo reversal of P-glycoprotein-mediated multidrug resistance by a novel potent modulator, XR9576. Cancer Res. 61:749-758.

16. Cirrito, J.R., et al. 2003. In vivo assessment of brain interstitial fluid with microdialysis reveals plaqueassociated changes in amyloid-beta metabolism and half-life. J. Neurosci. 23:8844-8853.

17. DeMattos, R.B., et al. 2004. ApoE and clusterin cooperatively suppress Abeta levels and deposition: evidence that ApoE regulates extracellular Abeta metabolism in vivo. Neuron. 41:193-202.

18. Sharma, V., and Piwnica-Worms, D. 2005. Monitoring multidrug resistance P-glycoprotein drug transport activity with SPECT and PET radiopharmaceuticals. Topics Curr. Chem. 252:155-178.

19. Dyszlewski, M., Blake, H.M., Dahlheimer, J.L., Pica, C.M., and Piwnica-Worms, D. 2002. Characterization of a novel $99 \mathrm{mTc}$-carbonyl complex as a functional probe of MDR1 P-glycoprotein transport activity. Mol. Imaging. 1:24-35.

20. Deane, R., et al. 2003. RAGE mediates amyloid-beta peptide transport across the blood-brain barrier and accumulation in brain. Nat. Med. 9:907-913.

21. Deane, R., Wu, Z., and Zlokovic, B.V. 2004. RAGE (yin) versus LRP (yang) balance regulates Alzheimer amyloid beta-peptide clearance through transport across the blood-brain barrier. Stroke. 35:2628-2631.
22. Hoffmeyer, S., et al. 2000. Functional polymorphisms of the human multidrug-resistance gene: multiple sequence variations and correlation of one allele with P-glycoprotein expression and activity in vivo. Proc. Natl. Acad. Sci. U. S. A. 97:3473-3478.

23. Marzolini, C., Paus, E., Buclin, T., and Kim, R.B. 2004. Polymorphisms in human MDR1 (P-glycoprotein): recent advances and clinical relevance. Clin. Pharmacol. Ther. 75:13-33.

24. Loeb, M.B., et al. 2004. A randomized, controlled trial of doxycycline and rifampin for patients with Alzheimer's disease. J. Am. Geriatr. Soc. 52:381-387.

25. Piwnica-Worms, D., Rao, V.V., Kronauge, J.F., and Croop, J.M. 1995. Characterization of multidrug resistance P-glycoprotein transport function with an organotechnetium cation. Biochemistry. 34:12210-12220.

26. Chen, W.S., et al. 2000. Effects of $M D R 1$ and $M D R 3$ P-glycoproteins, MRP1, and BCRP/MXR/ABCP on the transport of $(99 \mathrm{~m}) \mathrm{Tc}$-tetrofosmin. Biochem. Pharmacol. 60:413-426.

27. Luker, G.D., Rao, V.V., Crankshaw, C.L., Dahlheimer, J., and Piwnica-Worms, D. 1997. Characterization of phosphine complexes of technetium(III) as transport substrates of the multidrug resistance P-glycoprotein and functional markers of P-glycoprotein at the blood-brain barrier. Biochemistry. 36:14218-14227.

28. Holtzman, D.M., et al. 2000. Apolipoprotein E facilitates neuritic and cerebrovascular plaque formation in an Alzheimer's disease model. Ann. Neurol. 47:739-747.

29. Bales, K.R., et al. 1997. Lack of apolipoprotein E dramatically reduces amyloid beta-peptide deposition. Nat. Genet. 17:263-264.

30. Zlokovic, B.V., Mackic, J.B., Wang, L., McComb, J.G., and McDonough, A. 1993. Differential expression of $\mathrm{Na}, \mathrm{K}-\mathrm{ATP}$ ase alpha and beta subunit isoforms at the blood-brain barrier and the choroid plexus. J. Biol. Chem. 268:8019-8025. 